\title{
Pesquisar exige interrogar-se: \\ A narrativa como estratégia de pesquisa e de formação do(a) pesquisador(a)
}

\author{
Elisandro Schultz Wittizorecki ${ }^{1}$; Fabiano Bossle ${ }^{2}$; Lisandra Oliveira e Silva \\ Lusana Raquel de Oliveira ${ }^{4}$; Maria Cecília Camargo Günther \\ Marzo Vargas dos Santos ${ }^{6}$; Mônica Urroz Sanchotene ${ }^{7}$ \\ Rosane Kreusburg Molina ${ }^{8}$, Vera Regina Oliveira Dieh $l^{9}$
} Vicente Molina Neto ${ }^{10}$

Resumo: Este artigo registra a recente experiência dos(as) autores(as) num exercício de formação através da construção narrativa. Os objetivos, nesse exercício, foram o de aprender e o de interrogar-se sobre até que ponto os estudos que utilizam a perspectiva narrativa podem ser, concomitantemente, processos de formação e processos de investigação. A oportunidade de fazer essa aprendizagem, construída no interior do grupo, exigiu aprender a trabalhar nos limites do tensionamento da relação dialética entre o individual e o coletivo. Apresentamos, aqui, aprendizagens efetuadas com o exercício narrativo, suas possibilidades para o campo de estudos da formação de professores(as) e as limitações teórico-metodológicas encontradas.

Palavras-chave: Narrativas. Docente. Pesquisa qualitativa. Educação física. Pesquisadores.

\footnotetext{
Mestre em Ciências do Movimento Humano (UFRGS). Professor do Curso de Educação Física da ULBRA/Canoas.

${ }^{2}$ Mestre em Ciências do Movimento Humano (UFRGS). Professor dos Cursos de Educação Física na UNIVATES e FACOS.

${ }_{3}^{3}$ Mestranda em Ciências do Movimento Humano (UFRGS). Apoio: CAPES.

${ }^{4}$ Licenciada em Educação Física (UFRGS).

5 Doutoranda em Ciências do Movimento Humano (UFRGS). Professora da Rede Municipal de Ensino de Porto Alegre.

${ }^{6}$ Mestrando em Ciências do Movimento Humano (UFRGS). Professor da Rede Municipal de Ensino de Porto Alegre.

${ }^{7}$ Mestranda em Ciências do Movimento Humano (UFRGS). Professora da Rede Municipal

de Ensino de Porto Alegre. ${ }^{8}$ Doutora em Ciências da Educação (Universidad de Barcel
${ }^{9}$ Mestranda em Ciências do Movimento Humano (UFRGS)

Mestranda em Ciencias do Movimento Humano (UFRGS). ${ }^{10}$ Doutor em Ciências da Educação (Universidad de Barcelona). Professor de Graduação e Pós-Graduação na EsEF-UFRGS. Apoio: CNPq.

Os autores são integrantes do Grupo de Pesquisa Formação de Professores e Prática Pedagógica em Educação Física e Ciências do Esporte (F3P-EFICE), vinculado à Escola de Educação Física da Universidade Federal do Rio Grande do Sul e registrado no CNPq. Site: http://www.ufrgs.br/esef//3p-efice.
}

Movimento, Porto Alegre, v.12, n. 02, p. 09-33, maio/agosto de 2006. 


\section{Introdução}

Examinar as histórias de vida, as memórias, as narrativas dos sujeitos como possibilidade de produção do conhecimento não é exatamente novidade no campo do fazer científico, especialmente quando se trata de estudar os(as) docentes e seu trabalho. Nóvoa (2000, p.18) afirma que a utilização de "abordagens (auto) biográficas é fruto da insatisfação das ciências sociais em relação ao tipo de saber produzido e da necessidade de uma renovação dos modos de conhecimento científico". A própria Nova História emerge dessa insatisfação e dessa necessidade, trazendo à tona procedimentos metodológicos que vislumbram a história - ou a história - vista a partir de diversos olhares e de diversas fontes. As narrativas de professores (as) - procedimento metodológico que ora exploramos e procuramos aprender - representam, portanto, uma possibilidade dessa perspectiva de produzir outro tipo de conhecimento, mais próximo das realidades educativas e do cotidiano desses (as) professores (as).

"Não há experiência humana que não possa ser expressa na forma de uma narrativa" (BAUER; JOVCHELOVITCH, 2002). De alguma forma narramos. Narramos fatos, feitos, fenômenos. Narramos experiências, sentimentos, outras pessoas e nos narramos. Vale dizer que os textos científicos também se constituem, de forma elaborada, coesa e parametrizada, em narrativas: narram descobertas, compreensões, interpretações, recomendações. Portanto, narrar é dimensão fundamental de comunicação humana e de atribuição de significado ao mundo.

No entanto, as narrativas são infinitas em sua variedade, e nós as encontramos em todo o lugar. Bauer e Jovchelovitch (2002) afirmam que comunidades, grupos e culturas localizadas contam histórias, palavras e sentidos que são específicos à sua experiência e ao seu modo de vida, fazendo uso do "léxico do grupo social", o que constitui sua perspectiva de mundo. Dessa forma, pen- 
sar sobre as modalidades de narrativas ${ }^{1}$, no âmbito da reflexão sobre o trabalho e a formação de professores(as), significa ter contato com algumas categorias, concepções, descrições e formas de narrar e não com outras. Ou seja, professores(as) narrando suas trajetórias, sua construção, suas decisões revelam, provavelmente, conteúdos e discursos pautados pelas marcas e pela influência da cultura docente - muito diferente da narrativa de vinicultores, enfermeiros ou metalúrgicos.

Goodson (2000) destaca que há algum tempo está convencido que os estudos das histórias de vida dos (as) professores (as) são muito importantes na análise do currículo e da escolaridade, sobretudo porque "[....] podem ajudar-nos a ver o indivíduo em relação com a história do seu tempo, permitindo-nos encarar a intersecção da história de vida com a história da sociedade". (GOODSON, 2000, p.75). Ou seja, as narrativas podem ser um dos instrumentos que melhor viabilizam a coleta de informações, na perspectiva de mostrar ao investigador situações e explicações de que, parafraseando a obra de Hargreaves (1996), "cambiando os tempos, cambiam os professores" e suas ações.

Nosso grupo de pesquisa "Formação de Professores e Prática Pedagógica em Educação Física e Ciências do Esporte" (F3PEFICE) tem construído a maior parte de suas investigações (MOLINA NETO, 1996; GÜNTHER, 2000; SCHERER, 2000; BONONE, 2000; FAGGION, 2000; WITTIZORECKI; MOLINA NETO, 2005; BOSSLE, 2005; PEREIRA, 2004) tendo a etnografia como opção metodológica (MOLINA NETO, 1999). A partir de descrições densas (GEERTZ, 1989) temos buscado a compreensão dos significados atribuídos por professores (as) de Educação Física a seus modos de vida, crenças, valores, perspectivas, motivações e, como diz Woods (1995), as suas representações e rela1 Utilizamos essa expressão para dar conta das diferentes possibilidades de estudo e
ferramentas que visam, em última instância, trazer à tona memórias, episódios, biografias, enfim reconstruir a história dos sujeitos.

Movimento, Porto Alegre, v.12, n. 02, p. 09-33, maio/agosto de 2006. 
ções construídas e sustentadas no cotidiano escolar.

Aproximamo-nos da perspectiva narrativa nos primeiros meses de 2005 e iniciamos nossa trajetória pela leitura de "A Vida nas Escolas", de Peter McLaren (1997). Nesse livro, o autor faz referência à sua própria trajetória de professor, narrando, refletindo e se posicionando criticamente ante os acontecimentos vividos no cotidiano escolar. No decorrer da leitura e estudo desse texto surgiu a necessidade de discutirmos especificamente alguns questionamentos formulados pelo autor. Empreendemos, então, a tarefa de responder uma das questões ${ }^{2}$ proposta por McLaren (1997), com a intenção de refletir nossa ação na qualidade de professores(as) iniciantes, centrando o relato na experiência profissional, nas dificuldades encontradas e como construímos nossas soluções. Com o objetivo de qualificar nosso propósito de formação investigadores(as) - nos propusemos a elaborar uma narrativa escrita sobre a experiência de como nos tornamos professores(as).

Concomitantemente, o grupo identificou a necessidade de realizar uma revisão bibliográfica que sustentasse e qualificasse as reflexões sobre a perspectiva narrativa e sua utilização no campo da Educação Física. A revisão evidenciou indicativos interessantes sobre as possibilidades que tanto as histórias de vida quanto as narrativas autobiográficas oferecem aos processos de pesquisa e de formação de professores(as). Por exemplo, para Nóvoa (2000) o estudo a partir das experiências de vida dos professores(as) assume importância desde o final dos anos de 1970. Esse autor afirma que a sua aproximação com a perspectiva narrativa permitiu-lhe produzir e analisar sua própria história de vida, sua própria maneira de pensar e agir, tanto no campo da formação docente quanto da investigação. Por sua vez, Souza (2004) destaca o crescente número e a diversidade de pesquisas realizadas na

2 "Como você avaliaria meu papel como um professor iniciante? O que você teria feito diferente se você estivesse no meu lugar, e por quê?" (McLAREN, 1997, p. 226).

Movimento, Porto Alegre, v.12, n. 02, p. 09-33, maio/agosto de 2006. 
perspectiva (auto)biográfica, tanto no cenário internacional quanto no Brasil. A seguir, apresentamos nossas reflexões sobre alguns textos acadêmicos que tratam das narrativas e de seu uso no campo da Educação Física.

\section{A análise sobre o que lemos}

Uma busca nos arquivos de periódicos ${ }^{3}$ brasileiros específicos da Educação Física revelou, de imediato, a baixa ocorrência de artigos que adotam histórias de vida ou narrativas autobiográficas de professores(as) como referencial teórico-metodológico. A revisão totalizou cinco artigos publicados entre 1997 e 2005, assim distribuídos: três artigos em periódicos publicados em 1997, um em 2000 e igualmente um em 2005.

Após leituras cuidadosas desse acervo, procuramos caracterizá-las isoladamente e, num segundo momento, buscamos possíveis pontos de aproximação entre eles. A análise evidenciou um conjunto de abordagens bastante diverso, inclusive na forma de compreensão e no tratamento das histórias de vida e das narrativas autobiográficas.

No estudo de Betti e Mizukami (1997), elaborado a partir de uma entrevista semi-estruturada de caráter autobiográfico, histórias de vida aparecem como referencial teórico e a investigação é caracterizada como um estudo de caso, de natureza descritiva e analítica. As autoras tiveram como foco o resgate do processo de construção dos saberes docentes de uma professora de Educação Física aposentada ${ }^{4}$, interpretando os significados por ela atribuídos a esses saberes. A investigação centra-se no conhecimento

${ }^{3}$ Foram analisados os seguintes periódicos: Revista Brasileira de Ciências do Esporte (incluindo anais de Congresso Brasileiro de Ciências do Esporte), Motriz, Movimento, Licere, Pensar a prática, Conexões, Motus Corporis e Motrivivência.

${ }^{4}$ Esse artigo integra uma pesquisa mais ampla que investigou trajetórias pessoais e profissionais de professores aposentados de diferentes disciplinas.

Movimento, Porto Alegre, v.12, n. 02, p. 09-33, maio/agosto de 2006. 
como uma categoria importante no processo de formação docente e os diversos artigos que integram a obra "Vida de Professores", de António Nóvoa (2000) aparecem como principal referência.

No mesmo ano, foi publicado o artigo de Souza (1997) que discute as representações sociais da cultura negra através da dança e seus atores. Neste caso, história de vida aparece como técnica de entrevista, posteriormente submetida à análise de conteúdos de Bardin (1977). Segundo Bardin (1977), as categorias são elaboradas à luz da teoria das representações sociais no enfoque sociofilosófico marxista. Souza (1997, p. 29-30) destaca, ainda, que busca, através da metodologia escolhida, os "significados da fala do cidadão comum, do homem que está esquecido pela cultura dominante, a partir dos aviltamentos socioculturais que a população vive na sociedade moderna."

É interessante observar que, ao contrário de Betti e Mizukami (1997), nesse caso os colaboradores não são professores, mas atores. No entanto, o clássico de Nóvoa (2000) é novamente citado, e a aproximação pode ser justificada através da impossibilidade de isolar as experiências pessoais das profissionais. Nos dois textos, embora utilizados de forma diferente, a centralidade das experiências pessoais na constituição dos saberes necessários à vida profissional está fortemente evidenciada.

Para Betti e Mizukami (1997), a história de vida de uma professora, relatada em uma entrevista de caráter autobiográfica oferece indicativos para reflexões mais amplas em torno da formação de professores (as). Vale lembrar que, para essas autoras, história de vida é classificada como fonte ou como referencial teórico. Já, para Souza (1997), a história de vida é considerada uma técnica metodológica que possibilita uma "[...] apropriação da realidade dos sujeitos ao relatarem a sua experiência", à medi-

${ }^{5}$ A primeira edição desta obra data de 1992, ano que é referenciado no artigo consultado.

Movimento, Porto Alegre, v.12, n. 02, p. 09-33, maio/agosto de 2006 
da que, a partir das próprias narrativas, esses sujeitos representam seu referencial de vida. Souza também pondera que ao narrarem suas histórias os sujeitos têm, também, a possibilidade de re-elaborar a própria cultura corporal.

O texto de Capraro (2000), talvez, seja o que mais destoe em relação aos demais artigos revisados no nosso estudo. Para esse autor, a expressão história de vida não está vinculada à noção de referencial metodológico ou teórico. O autor discorre sobre o estilo da obra de Norbert Elias (1995), na qual a vida do famoso músico é narrada de forma que une literatura e análise sociológica. Trata-se, portanto, de uma análise crítica ao trabalho desenvolvido por Elias, destacando os méritos literários de sua obra aliados às concepções metodológicas próprias de outras obras também suas. Desse modo, a obra de Elias, segundo Capraro, utiliza com fluidez modelos macro e microssociológicos e chama a atenção para a forma pela qual o autor insiste na necessidade de que o leitor compreenda o individual através da influência da sociedade.

Recentemente, Ayoub (2005) apresentou sua investigação no XIV Congresso Brasileiro de Ciências do Esporte, em formato de comunicação oral, realizada entre os anos de 2002 e 2005. A autora reúne 290 cartas escritas por professoras integrantes da graduação, pós-graduação e cursos de extensão da Faculdade de Educação do Estado de São Paulo. As cartas, escritas ao longo do período citado, tratam das memórias da Educação Física escolar dessas professoras. Segundo a autora, as diferentes visões, expressas pelas colaboradoras, possibilitam a identificação de diferentes papéis que a Educação Física tem assumido ao longo dos anos. Destacamos, aqui, a forma como esse estudo foi desenvolvido. As narrativas foram escritas em formato de cartas, pois, segundo a autora, esse formato, "[ . . ] surgiu como uma possibilidade de deixar que as idéias fluíssem de forma mais solta, mais pessoal, atenuando as dificuldades da escrita que encontramos freqüentemente nos cursos de formação de professora" (AYOUB, 2005 , p. 3). A pesquisadora, estrategicamente, lançou mão de um

Movimento, Porto Alegre, v.12, n. 02, p. 09-33, maio/agosto de 2006. 
recurso que facilitou a desenvoltura de suas colaboradoras para a obtenção de relatos mais completos. A proposta foi feita de modo que as professoras imaginassem um(a) interlocutor(a) para quem iriam narrar suas lembranças.

Em relação à dinâmica da investigação, depois de escritas, as cartas foram trocadas para que fossem lidas por outras integrantes da turma. Seguiu-se à leitura uma discussão em pequenos grupos, em que as memórias foram tematizadas, de modo a buscar relações entre os diferentes papéis que a área tem assumido na escola. Nesse momento, os grupos deveriam ter o cuidado de registrar os pontos mais importantes dessas discussões. Na etapa seguinte, essas sínteses foram apresentadas para serem discutidas em grande grupo. A diferença de faixa etária entre as professoras possibilitou uma amplitude nos relatos que abrangeu um intervalo entre cinco e cinquienta anos atrás, conferindo grande diversidade e fazendo desse material um acervo importante para a pesquisa sobre os papéis da Educação Física escolar ao longo desse período. A análise do material possibilitou a elaboração de categorias a partir dos significados expressos pelas colaboradoras. O grupo das colaboradoras constitui-se de professoras ou estudantes de Pedagogia que exercem a docência em séries iniciais do Ensino Fundamental.

Revisamos, também, as dissertações apresentadas no Programa de Pós-Graduação em Ciências do Movimento Humano (PPGCMH) da Escola de Educação Física (EsEF) da Universidade Federal do Rio Grande do Sul (UFRGS), sendo que, das 147 pesquisas concluídas ${ }^{6}$, nenhuma foi construída sob a perspectiva teórico-metodológica da narrativa.

Essa breve revisão sobre as pesquisas realizadas em um Programa de Pós-Graduação de referência na área e sobre os recentes

${ }^{6}$ Esse número expressa o total de dissertações defendidas até 13 de junho de 2005 no referido Programa.

Movimento, Porto Alegre, v.12, n. 02, p. 09-33, maio/agosto de 2006. 
periódicos nos permite constatar, nas pesquisas da área de conhecimento da Educação Física e Ciências do Esporte, um predomínio de outros enfoques em detrimento de estudos de orientação fenomenológica-hermenêutica. As pesquisas que utilizam metodologias no paradigma das ciências sociais - as narrativas, mais particularmente - ainda são recentes na Educação Física, em que há uma tradição que privilegia determinados temas e metodologias identificadas com os estudos empírico-analíticos.

Enquanto que na Educação Física as narrativas constituemse em possibilidade metodológica de reduzida utilização, nas áreas de Letras, História e Pedagogia há uma série de estudos realizados nessa perspectiva há mais tempo. Fato que, de um lado, confere sentido à nossa discussão e, de outro, evidencia a situação de insipiência metodológica em que se encontra a Educação Física em comparação com essas áreas de conhecimento.

Nossa intenção não é a de protagonizar uma inovação metodológica, mas, sobretudo, a de experimentar a perspectiva narrativa como instrumento de produção de conhecimento e de formação docente no âmbito da Educação Física.

Nossa primeira leitura específica sobre narrativa foi "Experiências de Vida e Formação", de Marie-Christine Josso (2004). Para essa autora, a perspectiva que favorece a construção de uma narrativa emerge do embate paradoxal entre o passado e o futuro em favor do questionamento presente. A construção da narrativa na formação emprega o recurso de recordações-referências para compreender como nos formamos por meio de um conjunto de experiências ao longo da vida, ou seja, propõe a "narração de si mesmo" a partir de questionamentos sobre o que é minha formação e como me formei. Para Josso (2004), uma experiência vivenciada torna-se formadora quando considera as aprendizagens passadas que simbolizam as atitudes, os pensamentos, o saberfazer e os sentimentos do presente, sob a ótica de um processo de "caminhar para si":

Movimento, Porto Alegre, v.12, n. 02, p. 09-33, maio/agosto de 2006. 
O processo de caminhar para si apresenta-se, assim, como um projeto a ser construído no decorrer de uma vida, cuja atualização consciente passa, em primeiro lugar, pelo projeto de conhecimento daquilo que somos, pensamos, fazemos, valorizamos e desejamos na nossa relação conosco, com os outros e com o ambiente humano e natural (JOSSO, 2004, p.59).

Larrosa (2004), em "A Aventura (Auto) Biográfica: teoria e empiria", afirma que a consciência de si no presente é sempre consciência de quem somos neste preciso momento de nossas vidas, destacando a temporalidade da narração em atividades de uso da memória:

Recordar é algo que nós fazemos e para isso necessitamos da oportunidade, o encontro da imaginação e a habilidade da composição. Por isso, a memória tem a forma de uma narração desde um ponto passado até o presente em funcão de um ponto de vista que se faz significativo (LARROSA, 2004, p. 16).

Esse caráter temporal da experiência humana é destacado por Abrahão (2004) quando afirma que a memória é elementochave do trabalho com pesquisas biográficas. Para essa autora, o(a) pesquisador(a) trabalha para poder reconstruir elementos rememorados que permitam a compreensão de seu objeto de estudo - o sujeito, com isso, articula memória e conhecimento buscando edificar uma "arqueologia da memória". Nesse processo de narração, destaca Souza (2004), há a necessidade de compreensão de que cada sujeito representa o fato vivido através de escolhas à luz de uma memória seletiva, e o reconstrói de forma peculiar, de maneira intencional ou não:

A verdade passa a incorporar um vínculo direto com a subjetividade/profundidade do indivíduo, exprimindo-se na categoria sinceridade e ganhando, ela mesma, uma dimensão fragmentada e impossivel de sofrer controles absolutos. A verdade, não mais unitária, mas sem

Movimento, Porto Alegre, v.12, n. 02, p. 09-33, maio/agosto de 2006. 
prejuizo de solidez, passa a ser pensada em sentido plural, como são plurais as vidas individuais, como é plural e diferenciada a memória que registra os acontecimentos da vida (GOMES, 2004, p.14).

A idéia de verdade na perspectiva da "escrita de si" está no assumir a subjetividade de seu autor como dimensão integrante da linguagem, construindo a "sua" verdade na narrativa (GOMES, 2004). Para essa autora não compete ao pesquisador dizer "o que houve ou não" (o que realmente aconteceu), mas compreender o que autor diz que viu e experimentou em relação ao real e ao vivido, ou, como afirma Ben-Peretz (2000), de que modo o ser humano "sente" o mundo.

Becker (1999), ao apresentar o método (auto)biográfico, diz que há uma "versão selecionada" do que cada sujeito quer narrar ou do que prefere mostrar aos outros. Como essa abordagem de pesquisa está centrada no sujeito e nas suas experiências pode haver riscos na utilização da memória como fonte de análise. Nesse sentido, o autor defende a utilização de outras fontes que possam ser articuladas com a abordagem (auto)biográfica, constituindo um "mosaico" em que cada peça contribui para a compreensão do quadro como um todo. Essa proposição metodológica se aproxima da perspectiva de Abrahão (2004), de Gómez; Flores e Jiménez (1996), de Taylor e Bogdan (1996), entre outros autores, que sugerem a adoção do procedimento da triangulação das fontes.

O procedimento de triangular informações é adotado por nosso grupo de pesquisa. Realizamos muitas de nossas investigações na perspectiva etnográfica, utilizando instrumentos de coleta das informações como a observação participante, a entrevista, os registros em diário de campo e a análise de documentos. A triangulação das informações é um procedimento adotado no processo analítico a que essas informações são submetidas.

Dessa forma, entendemos que a narrativa, como instrumento

Movimento, Porto Alegre, v.12, n. 02, p. 09-33, maio/agosto de 2006. 
de produção de conhecimento, é uma interessante opção na construção dos "mosaicos" de informações que objetivam compreender os significados que os(as) professores(as) de Educação Física atribuem ao seu fazer cotidiano, à sua formação e às micropolíticas presentes no universo das escolas, porque narrar é considerar percursos de vida e entrar em contato com lembranças (distantes ou próximas), sentimentos e subjetividades, ou seja, é "caminhar para si".

\section{0 processo narrativo que experienciamos}

Primeiramente comecei a pensar sobre minhas experiências, não de forma cronológica, mas buscando 'voltar no tempo' e entender por que elas aconteceram desse jeito e não de outro. Quais escolhas tive que fazer? O que priorizei quando comecei a dar aula? Começo a perceber, que na vida, ou ao menos na vida de uma professora iniciante, não temos tempo ou não damos a devida importância para entender as coisas que fazemos. Vamos estudando, ao mesmo tempo em que trabalhamos, realizamos estágios, vamos vivendo da forma que nos é possivel ${ }^{7}$ (Ana, maio de 2005).

Iniciamos a construção desse trabalho com a elaboração de narrativas escritas individuais sobre a experiência docente de cada um(a). O ponto de partida consensual foi a questão proposta por McLaren (1997), que indaga sobre o que faríamos no lugar dele, referindo-se às situações vividas no início da sua carreira docente. Vale ressaltar que esse exercício de narrar a experiência docente foi o primeiro contato que muitos de nós tivemos com a narrativa escrita. O nosso grupo reúne participantes de diferentes graus de experiência docente e de diferentes níveis de formação, desde estudantes de graduação em Educação Física até professores(as) e doutores(as) com experiência em pesquisa.

${ }^{7}$ Fragmento de uma das narrativas construídas por uma integrante de nosso grupo de pesquisa. Seu nome verdadeiro foi preservado.

Movimento, Porto Alegre, v.12, n. 02, p. 09-33, maio/agosto de 2006. 
As discussões iniciais tiveram o objetivo de orientar as decisões metodológicas em torno do processo de organização e de análise dos textos produzidos. Os textos escritos individualmente sobre as experiências foram socializados com o grupo, para que cada participante conhecesse as experiências dos colegas, através das respectivas narrativas. Na continuação do processo optamos pela ampliação das narrativas a partir das reflexões advindas desse diálogo coletivo.

Ao mesmo tempo em que avançávamos na análise das experiências narradas, identificamos a necessidade de aprofundar nossa compreensão conceitual sobre a perspectiva narrativa como instrumento de formação e de produção de conhecimento. Nossa intenção de utilizar narrativas no projeto coletivo de pesquisa ${ }^{8}$ nos auto-impunha essa exigência.

Posteriormente à etapa inicial de leituras e aprofundamento teórico sobre o tema ${ }^{9}$, relemos as narrativas e elaboramos questionamentos ao conjunto delas. Essa atividade teve como objetivo provocar a explicitação da vivência de cada um(a) neste processo e nossas diferentes percepções sobre essa experiência.

As discussões que se seguiram foram pautadas por debates conceituais sobre a concepção de biografia, autobiografia e narrativa. Esse processo centrou-se em articular e apreender conexões e distinções entre esses termos. Portanto, considerando a necessidade de melhor compreender esses conceitos e outros que surgiram, o grupo realizou um novo levantamento bibliográfico sobre narrativas que foi socializado e discutido entre seus integrantes.

A seguir, cada participante escreveu um texto pretendendo

${ }^{8}$ Pesquisa financiada pelo CNPq, através de Bolsa de Produtividade de Pesquisa e coordenado pelo Prof. Dr. Vicente Molina Neto: "A Formação Profissional e a Prática Pedagógica dos Professores de Educação Física da Rede Municipal de Ensino de Porto Alegre: relações emergentes e efeitos gerados pelas transformações sociais e profissionais no trabalho e na vida dos docentes".

9 Revisão bibliográfica registrada nesse artigo sob o título: $A$ análise sobre o que lemos.

Movimento, Porto Alegre, v.12, n. 02, p. 09-33, maio/agosto de 2006. 
responder o seguinte questionamento: o que aprendi sobre investigação narrativa? Os textos produzidos contemplaram a seguinte abordagem: a) as diferentes visões a respeito do tema na literatura; b) a importância da narrativa na investigação; c) as aprendizagens identificadas no processo.

A partir das produções individuais e das partilhas coletivas, nos empenhamos na produção dessa publicação cujo objetivo é discutir e disponibilizar subsídios para pensar a narrativa como opção metodológica nos processos de formação de professores(as) em Educação Física.

Ao compartilhar nossa experiência, através dessa publicação, com um universo mais amplo de "outros", reafirmamos o que diz Warschauer apud Josso (2004): "a experiência narrada transformase, assim, na experiência daqueles que ouvem a história" (p. 10).

\section{Reflexões acerca do que aprendemos ao narrarmo-nos}

Para mim, o que tem acontecido é um processo de aprofundamento que me faz lembrar Peter Woods (1995) que sugere que o trabalho de campo nos leva a 'descobrir camadas' que vão se revelando e nos permite mergulhar na realidade investigada. Experimento um sentimento parecido com esse, mas mergulhando em direcão a camadas mais profundas da minha/nossa própria história (João, maio de 2005). ${ }^{10}$

Nosso objetivo ao narrarmo-nos foi o de perceber, no tensionamento da relação dialética entre o individual e o coletivo, quanto os estudos que usam a perspectiva narrativa podem ser, ao mesmo tempo, formação e investigação. Assim, ao reconstruirmos nossa experiência de maneira reflexiva, fomos desvelando os significados que atribuímos aos fatos que vivemos, realizando uma

${ }^{10}$ Fragmento de uma das narrativas construídas por um integrante do nosso grupo de pesquisa. Seu nome verdadeiro foi preservado.

Movimento, Porto Alegre, v.12, n. 02, p. 09-33, maio/agosto de 2006. 
espécie de auto-análise que possibilitou compreender melhor as escolhas que fizemos. A capacidade de narrar a si mesmo, além de envolver a capacidade de refletir sobre a experiência vivida, pode ajudar a entender e a organizar a realidade social e, dessa forma, oferecer melhores condições para que os sujeitos possam transformar a própria realidade.

As lembranças de alguns acontecimentos da experiência profissional se tornam significativas no sentido de perceber que lembrar não emerge no vazio. A narrativa vai além de lembrar os acontecimentos vividos no cotidiano, pois tem a influência tanto da dimensão coletiva quanto da individual. Escrever a respeito de si, além de envolver a reflexão da experiência vivida no processo coletivo pode nos levar a conhecer a multiplicidade da realidade social e nossa relação com essa realidade. Nesse sentido, as experiências individuais são as expressões de uma realidade social que o sujeito organizou e das quais se apropriou. Segundo Bueno (2002 p.19), "o indivíduo é sujeito ativo no processo de apropriação do mundo social, traduzido em práticas que manifestam a sua subjetividade." Sendo assim, a experiência individual não está isolada da experiência social, é o conjunto de características próprias e variadas de experiências singulares que a realidade social manifesta.

A questão da singularidade de um indivíduo versus o contexto social e histórico em que está inserido (GOLDENBERG, 2002) também merece atenção. Josso (2004) argumenta em prol do individual e do coletivo em forma de polaridade: de um lado, a nossa interpretação - "auto-interpretação" - e, de outro, o diálogo com os outros, uma "co-interpretação". Ainda segundo a autora, "é neste movimento dialético que nos formamos como humano" (JOSSO, 2004, p.54). Desse modo, é no espaço da relação dialética entre o individual e o coletivo que podemos perceber que os estudos que usam como instrumento a narrativa e as histórias de vida são, ao mesmo tempo, investigação e formação.

Movimento, Porto Alegre, v.12, n. 02, p. 09-33, maio/agosto de 2006. 
Segundo Bourdieu (1996), o fato de as narrativas estarem circunscritas ao universo metodológico das biografias, poderíamos pensar a "vida como história". Avançando na compreensão metodológica sobre a história de vida, Gómez; Flores e Jiménez (1996) propõem a delimitação conceitual entre relatos de vida e história de vida, em que os primeiros seriam a história de uma vida tal como uma pessoa viveu e contou e, na segunda, a perspectiva de um estudo de caso sobre uma pessoa, quando, então, se busca a compreensão de seu relato de vida na interação com outras informações ou documentos (pessoais ou oficiais) que possibilitem a reconstrução da trajetória de um ou mais aspectos de sua vida, por exemplo, a formação.

Nesse sentido, a partir do texto de Paul Ricoeur (1999) Historia y Narratividad - é possível estabelecer distinção entre narrativa como relato e a narrativa como perspectiva investigativa. No primeiro caso, estamos falando de, pelo menos, três eixos distintos: história de vida, biografia e autobiografia. No segundo caso, estamos falando de uma nova perspectiva (como uma qualificação da pesquisa qualitativa) da investigação qualitativa. Ou seja, estamos falando de metodologia da pesquisa qualitativa. Neste caso, podemos encontrar ou produzir: o relato único (de um docente, de um informante); relatos paralelos (como diferentes indivíduos vivem uma mesma experiência); polifonia de relatos (analisar a polifonia das fronteiras entre diferentes relatos).

As combinações que se venha a fazer em um projeto de pesquisa qualitativa, na busca de evidências/informações, têm relação com o problema de investigação construído. Cabe dizer que o relato biográfico tem sido mais freqüentemente identificado nos exercícios narrativos, tanto os que têm objetivado a formação (relatos reflexivos) quanto os casos de objetivar construção/produção de conhecimento (re-construção hermenêutica).

Cremos que as narrativas - a partir da experiência própria que desenvolvemos - pelo fato de serem textos escritos, podem

Movimento, Porto Alegre, v.12, n. 02, p. 09-33, maio/agosto de 2006. 
ser mais disciplinadoras - não no sentido da censura, mas no sentido reflexivo dos discursos. Ou seja, a textualidade exige outra qualidade e outro esforço ao sujeito-autor, preocupações geralmente não-presentes na oralidade, tanto na expressão quanto na compreensão, na ênfase e nos limites das situações narradas. É nesse argumento que concordamos com a afirmação de que a narrativa é ou pode vir a ser um aprofundamento, uma qualificação ou ainda um requinte disponível para a metodologia da pesquisa qualitativa.

Segundo Zussman:

$$
\begin{aligned}
& \text { Las narraciones autobiográficas - los relatos } \\
& \text { que contamos sobre nosotros mismos, no } \\
& \text { representan simplemente el yo. Tampoco lo } \\
& \text { expresan simplemente. Las narraciones } \\
& \text { constituyen el yo...(Si) las narraciones autobio- } \\
& \text { gráficas constituyen el yo, esas narraciones son } \\
& \text { estructuradas socialmente. Si queremos } \\
& \text { comprender y explicar el yo...(si) queremos en- } \\
& \text { tender las variaciones que se producen a lo lar- } \\
& \text { go del tiempo y em distintos lugares, entonces } \\
& \text { hemos de prestar tanta atención a las estructuras } \\
& \text { sociales que producen las narraciones autobio- } \\
& \text { gráficas como a las propias narraciones } \\
& \text { (ZUSSMAN apud SPARKES, 2003, p.5). }
\end{aligned}
$$

Nessa perspectiva, as narrativas não refletem de modo linear ou simples as experiências reais do sujeito que narra. As pessoas que narram vêem-se obrigadas a recorrer a modos lingüísticos ou, em palavras de Bernard Charlot (2000), a práticas linguageiras com as quais estão familiarizadas para narrar suas histórias. Por isso, sem dúvida, a narrativa é também uma forma de prática social através da qual o sujeito elege/escolhe/busca/constrói, a partir de um repertório sociocultural de relatos (coletivo), o que melhor expressa a sua narrativa pessoal, ou seja, a sua história.

Ricoeur (1999), falando sobre a identidade narrativa, traz valiosa contribuição para a compreensão da identidade que o su-

Movimento, Porto Alegre, v.12, n. 02, p. 09-33, maio/agosto de 2006. 
jeito humano alcança mediante a função narrativa: a narrativa expõe um aspecto do conhecimento de si que supera em muito os limites do próprio relato. Com essa afirmação, Ricoeur pretende nos convencer de que a ação de conhecer-se a si mesmo não é ato possível de um modo imediato. Conhecer-se a si mesmo, a partir da narrativa, só é possível de forma indireta, ou seja, mediante um processo analítico cuidadoso de todos os signos culturais mais amplos presentes no próprio relato. Com esse argumento, Ricoeur recorda-nos a óbvia compreensão de que a ação humana sempre se encontra simbolicamente mediatizada.

Concordando com Sparkes (2003), a narrativa tem a ver com contar histórias. Portanto, ao dizê-las, escutá-las e escrevêlas, aumentam as chances de compartilhar experiências sobre nossas vidas e as vidas de outras pessoas. O interesse dos(as) pesquisadores(as) qualitativos pelas narrativas tem aumentado porque, segundo o autor, é a forma lingüística que melhor se adapta à compreensão da historicidade da experiência humana como uma ação contextualizada. As descrições narrativas mostram a atividade humana como um compromisso com propósitos e apostas no mundo. Comenta, ainda, o autor, referindo-se a outros pensadores, que a análise de narrativas (tarefa da pesquisa qualitativa) é uma forma de abrir uma janela na mente do narrador ou, se estivermos analisando narrativas de um determinado grupo específico - no nosso caso, como foco de interesse, professores(as) de Educação Física - é uma forma de abrir uma janela à sua cultura (cultura desse coletivo docente).

\section{Considerações finais}

A experiência que temos acumulado com pesquisas qualitativas que têm utilizado a entrevista como um de seus principais instrumentos nos faz entender e, talvez, concordar com Goodson (2005) quando afirma que, através da análise das entrevistas, o que temos feito são construções de visões instrumentais do pro-

Movimento, Porto Alegre, v.12, n. 02, p. 09-33, maio/agosto de 2006. 
fessorado. Ou seja, por mais que não queiramos e não desejamos, acabamos reduzindo-os à categoria de objetos que podem ser manipulados (processos analíticos) para alcançarmos determinados fins (conhecimentos pretendidos nos nossos projetos de pesquisa).

Através das narrativas ou da metodologia narrativa (histórias de vida), talvez possamos efetivamente evidenciar coerência ou conferir-lhe coerência, através da produção de conhecimentos, com o desejo dos(as) professores(as) de dar sentido a suas vidas pessoais e profissionais.

No exercício contínuo de pensar procedimentos metodológicos adequados aos nossos objetos de estudo e, sobre as aprendizagens que ora estamos efetuando a partir da discussão e reflexão de nossas narrativas quando professores(as) iniciantes, e mesmo em outros coletivos docentes e/ou com outros propósitos, entendemos - parafraseando Josso (2004) - há necessidade de atingir uma produção de conhecimentos que tenha sentido para os sujeitos e que os próprios se inscrevam em um projeto de conhecimento que os institua sujeitos. $\mathrm{O}$ fato de constituirmos um grupo de estudo e de investigação nos alavanca com determinada intencionalidade e disposição ao nos narrarmos e ao refletirmos sobre essas narrativas. Identificamos momentos de ruptura e transformação em nossas formas de fazer e de pensar; identificamos a influência de acontecimentos pessoais e sociais em nossa opção pela docência e seus rumos; e identificamos a construção e a mudança de estilos de ser professor(a). Muito provavelmente, esse mesmo exercício feito por outros coletivos possibilitará aprendizagens e reflexões diferenciadas e, talvez, até similares. De qualquer forma, o que queremos ressaltar é que esse exercício, o de narrar-se, com vistas à formação, de acordo com a proposição de Josso (2004), articula conhecimentos, representações, técnicas e significados singulares a cada indivíduo ou grupo, mas, simultaneamente, representativos de uma coletividade mais ampla onde grupo

Movimento, Porto Alegre, v.12, n. 02, p. 09-33, maio/agosto de 2006. 
e indivíduos se inserem.

Por outro lado, Ferrarotti apud Bueno (2002) adverte, em relação ao uso do método biográfico:

\begin{abstract}
[. . . ] apelar para a representatividade da biografia significa negar o caráter histórico do método - uma vez que se trata da história de uma vida - e o pressuposto da subjetividade nele contido. Escolhidas a priori, com base em critérios preestabelecidos, as biografias assim utilizadas não são tomadas como fontes para novos conhecimentos, mas sim para descrever ou verificar aquilo que já está contido no modelo formal (FERRAROTTI apud BUENO, 2002, p.18).
\end{abstract}

Com isso, chamamos a atenção para as contestações que essa metodologia recebe de alguns estudiosos da área. A obra de Nóvoa (2000) corrobora esse alerta e faz emergir os modismos e os riscos de lidar com a questão das subjetividades no campo da formação de professores(as). É o próprio Ferrarotti que sugere a saída para esse problema, à medida que mostra que a relação entre história social e história individual não é linear, nem automática; e que pensar em termos de quantidade de narrativas é um equívoco para avalizar um estudo. Segundo o autor:

[. . . ] o nosso sistema social encontra-se integralmente em cada um dos nossos atos, em cada um dos nossos sonhos, delírios, obras, comportamentos. E a história deste sistema está contida por inteiro na história da nossa vida individual (FERRAROTTI apud BUENO, 2002, p. 19).

Dessa forma, vislumbrando a formação e o trabalho de professores(as) de Educação Física nas escolas, entendemos que o exercício do narrar-se é uma alternativa interessante de devolver ao professor(a) o protagonismo de sua trajetória, mas, ao mesmo tempo, é possível antevê-lo como um procedimento metodológico de 
alguma dificuldade, por duas razões. A primeira, pelas questões já sabidas e experimentadas de construção de vínculo e confiança com os(as) colaboradores(as). A segunda consiste na dificuldade ou quase ausência do hábito que o coletivo docente tem de registrar, sistematizar e produzir textualmente a partir do seu trabalho.

Inegavelmente, narrar a si mesmo constitui um exercício de introspecção, e como declara Josso (2004), exige uma perspectiva de caminhar para si. Esse caminhar para dentro de si exige tempo e tranqüilidade para buscar lembranças, requisitá-las e selecionálas no imenso silêncio dos esquecimentos - conscientes e inconscientes. Catani e Vicentini (2003) abordam esse aspecto:

Quando os sujeitos se voltam para o passado para produzir uma escrita autobiográfica, eles não só sofrem a influência do distanciamento temporal que atua em todo processo memorialístico, apagando determinadas experiências $e$ intensificando outras, mas também operam uma seleção, ao escolher os fatos considerados dignos de ser divulgados e ao privilegiar determinados aspectos em detrimento de outros, em busca de dar sentido ao relato da própria vivência. (CATANI;VICENTINI, 2003, p. 153)

Esse movimento de lembrar/esquecer parece, de fato, uma tentativa de dar sentido ao vivido conforme os significados que atribuímos aos acontecimentos. Parece-nos possível, no entanto, que esses significados não sejam definitivos. Certamente, nossas narrativas reescritas em outro momento histórico - passado ou vindouro - poderiam apresentar outras ênfases e outras omissões.

Movimento, Porto Alegre, v.12, n. 02, p. 09-33, maio/agosto de 2006. 
To Research Require Question Yourself: The Narrative as Research Strategy and Training Researcher.

Abstract: This article registers the recent author's experience in a formation exercise through the construction narrative. The group's objectives, in this exercise, were to learn and to interrogate itself on until point the studies which use the perspective narrative can be, at the same time, processes of formation and processes of inquiry. The chance to make this learning, constructed in the interior of the proper group demanded us all the time, learn to work in the tension's limits of the dialectic relation between individual and the collective one. In this article we disclose the joined learnings that we effect with the narrative exercise, its possibilities for the formation teachers studies field and the theorist methodological limitations found.

Keywords: Narration. Faculty. Qualitative research. Physical Education. Research personal.

Pesquisar exige cuestionarse: la narrativa como estrategia de pesquisa y de formación del pesquisador.

Resumen: Este artículo registra la reciente experiencia de los(as) autores(as) en un ejercicio de formación por medio de la construcción narrativa. Los objetivos del grupo, en el ejercicio, fueron el de aprender y de preguntarse sobre hasta que punto los estudios que utilizan la perspectiva narrativa, pueden ser, al mismo tiempo, procesos de formación y procesos de investigación. La oportunidad de hacer ese aprendizaje, construido en el interior del grupo, nos ha exigido aprender a trabajar en los límites de la tensión de la relación dialéctica entre el individual y el colectivo. En este artículo presentamos los aprendizajes que efectuamos con el ejercicio narrativo, sus posibilidades para el campo de estudios de la formación de profesores(as) y las limitaciones teórico-metodológicas encontradas.

Palabras-clave: Narración. Docente. Investigación cualitativa. Educación Física. Investigadores. 


\section{REFERÊNCIAS}

ABRAHÃO, M. H. M. B. (org). A Aventura (Auto) Biográfica: teoria e empiria. Porto Alegre: EDIPUCRS, 2004.

AYOUB, E. Memórias de Educação Física escolar. In: CONGRESSO BRASILEIRO DE CIÊNCIAS DO ESPORTE, 14. 2005. Anais ...Porto Alegre: Escola de Educação Física da UFRGS, 2005. CD-ROM.

BARDIN, L.. Análise do conteúdo. São Paulo: Persona, 1977.

BAUER, M.; JOVCHELOVITCH, S. Entrevista Narrativa. In: BAUER, M.; GASKELL, G. Pesquisa qualitativa com texto, imagem e som. Petrópolis: Vozes, 2002.

BECKER, H. S. Métodos de pesquisas em Ciências Sociais. São Paulo: Hucitec, 1999

BEN-PERETZ, M. Episódios do passado evocados por professores aposentados. In: NÓVOA, António (org.). Vidas de professores. Porto: Editora Porto, 2000.

BETTI, I. R. e MIZUKAMI, M. G. N. História de vida: trajetória de uma professora de Educação Física. Motriz, Rio Claro, v. 3, n. 2, p. 108-115, dez. 1997.

BONONE, C. G. G. A prática da educação física na escola privada de ensino médio de Caxias do Sul-RS: perspectiva do professor. Porto Alegre: UFRGS, 2000. Dissertação (Mestrado em Ciências do Movimento Humano), Escola de Educação Física, Universidade Federal do Rio Grande do Sul. Porto Alegre, 2000.

BOSSLE, F. Planejamento de Ensino dos Professores de Educação Física: um estudo etnográfico na Rede Municipal de Ensino de Porto Alegre. In: FIGUEIREDO, Z. C. C. (org.). Formação profissional em Educação Física e mundo do trabalho. Vitória: Faculdade Salesiana, 2005.

BOURDIEU, P. A llusão Biográfica. In: FERREIRA, M. de M.; AMADO, J. Usos e Abusos da História Oral. Rio de Janeiro: FGV, 1996.

BUENO, B. O. O método autobiográfico e os estudos com histórias de vida de professores: a questão da subjetividade.Educação e Pesquisa, São Paulo, v.28, n.1, p. 11-30, jan./jun. 2002.

CAPRARO, A. M. História de vida, identificação e sentimentos: Norbert Elias e o homem que viveu fora do seu tempo. Conexões: educação, esporte, lazer. Campinas, n.5, p. 19-26, dez. 2000.

CATANI, D. B.; VICENTINI, P. P. "Minha vida daria um romance": lembranças e esquecimentos, trabalho e profissão nas autobiografias de professores. In: MOGNOT, M. T.; CUNHA, M. T. S. Práticas de memória docente. São Paulo: Cortez, 2003.

Movimento, Porto Alegre, v.12, n. 02, p. 09-33, maio/agosto de 2006. 
CHARLOT, B. Práticas linguageiras e fracasso escolar. In: ENCONTRO NACIONAL DE ESTUDANTES DE LETRAS (ENEL). Cuiabá, 18 jul. 2000. Palestra. ELIAS, Norbert. Mozart: sociologia de um gênio. Rio de Janeiro: Jorge Zahar, 1995.

FAGGION, C. A. A prática docente dos professores de Educação Física do ensino médio das escolas públicas de Caxias do Sul. 2000. Dissertação (Mestrado em Ciências do Movimento Humano). - Escola de Educação Física, Universidade Federal do Rio Grande do Sul, Porto Alegre, 2000.

GEERTZ, C. A Interpretação das culturas. Rio de Janeiro: LTC, 1989.

GOLDENBERG, M. A Arte de pesquisar. Rio de Janeiro: Record, 2002.

GOMES, A. A. Escrita de si, escrita da história. Rio de Janeiro: Editora FGV, 2004.

GOMÉZ, G. R.; FLORES, J. G.; JIMÉNEZ, E. G. Metodologia de la investigación cualitativa. Barcelona: Aljibe, 1996.

GOODSON, I. Professorado e histórias de vida. (Prólogo da edição espanhola). Tradução de Fernando Hernandez. Barcelona: Octaedro, 2005.

GOODSON, I. Dar voz ao professor: as histórias de vida dos professores e o seu desenvolvimento profissional. In: NÓVOA, A. (org.). Vidas de Professores. 2. ed. Porto: Porto Editora, 2000.

GÜNTHER, M. C. C. A Formação permanente de professores de Educação Física na rede municipal de ensino de Porto Alegre no período entre 1989 à 1999: um estudo a partir de quatro escolas da Rede. 2000. Dissertação (Mestrado em Ciências do Movimento Humano).- Escola de Educação Física, Universidade Federal do Rio Grande do Sul, 2000.

HARGREAVES, A. Profesorado, cultura y postmodernidad: cambian los tiempos, cambia el profesorado. Madrid: Morata, 1996.

JOSSO, M. C. Experiências de vida e formação. São Paulo: Cortez, 2004.

LARROSA, J. Notas sobre Narrativa e Identidade. In: ABRAHÃO, M. H. M. B. (org.) A Aventura (Auto) Biográfica: teoria e empiria. Porto Alegre: EDIPUCRS, 2004.

McLAREN, P. A vida nas escolas: uma introdução à pedagogia crítica nos fundamentos da educação. 2. ed. Porto Alegre: ARTMED, 1997.

MOLINA NETO, V. La cultura escolar del professorado de Educación Física de las escuelas públicas de Porto Alegre. 1996. Tese (Doctorado en Filosofía y Ciencias de la Educación), Departamento de Educación, Universidad de Barcelona, 1996.

MOLINA NETO, V.. Etnografia: uma opção metodológica para alguns problemas de investigação no âmbito da educação física. In: MOLINA NETO, V.; TRIVIÑOS, A 
N. S. A pesquisa qualitativa na Educação Física. Porto Alegre: UFRGS: Sulina, 1999.

NÓVOA, A. Os Professores e as Histórias de Vida. In: NÓVOA, António (org.). Vidas de professores. Porto: Porto Editora, 2000.

PEREIRA, R. R. A interdisciplinaridade na ação pedagógica do professor de educação física da rede municipal de ensino de Porto Alegre. 2004. Dissertação (Mestrado em Ciências do Movimento Humano).- Escola de Educação Física, Universidade Federal do Rio Grande do Sul, 2004.

RICOEUR, P. Historia y narratividad. Barcelona: Paidós, 1999.

SCHERER, A. O conhecimento pedagógico do professor de Educação Física na escola pública da rede Estadual de ensino e sua relação com a prática docente. 2000. Dissertação (Mestrado em Ciências do Movimento Humano).Escola de Educação Física, Universidade Federal do Rio Grande do Sul, 2000.

SOUZA, E. C. O. Conhecimento de si: as narrativas de formação e o estágio: reflexões teórico-metodológicas sobre uma abordagem experiencial de formação inicial de professores. In: ABRAHÃO, M. H. M. B. (org.). A aventura (auto) biográfica: teoria e empiria. Porto Alegre: EDIPUCRS, 2004.

SOUZA, E. F. Histórias de vida? A memória resgatada através da atividade corporal. In: Revista Motus Corporis, Rio de Janeiro, v.4, n.1, p. 27-41, 1997.

SPARKES, A. C. Investigación narrativa em la educación física y el deporte. Revista agora para la EF y el Deporte, Valladolid, n. 2-3, p. 51-60, 2003.

TAYLOR, S. J.; BOGDAN, R. Introducción a los métodos cualitativos de investigación. Barcelona: Paidós, 1996.

WITTIZORECKI, E. S.; MOLINA NETO, V. O trabalho docente dos professores de Educação Física na Rede Municipal de Ensino de Porto Alegre. Movimento. Porto Alegre, v. 11, n. 1, p. 47 - 70, jan./abr. de 2005.

WOODS, P. La Escuela por dentro: la etnografia en la investigación educativa. Barcelona: Paidós, 1995. 